\author{
이현지 \\ 경성대학교 의상학과
}

\title{
The Clothing Consumption Behavior of Fast Fashion Purchaser according to Environmental Consciousness
}

\author{
Hyun Ji Lee ${ }^{\dagger}$ \\ Dept. of Fashion Design \& Merchandising, Kyungsung University; Busan, Korea
}

\begin{abstract}
This study investigates clothing consumption behavior of fast fashion purchasers according to environmental consciousness. Questionnaire examined 245 males and females in Busan who experienced fast fashion product purchases. Data were analyzed using factor analysis, t-test. ANOVA, Duncan Test and $\chi^{2}$-test. The results are as follows. First, the result showed significant differences in environmental consciousness education according to demographic characteristics. Second, the results showed significant differences in the hedonic pursuit of purchase motivation for fast fashion products according to environmental consciousness. The low environmental awareness group pursued hedonic purchases towards the purchase motivation of fast fashion products. The results showed significant differences in fast fashion disposal behavior according to environmental consciousness; however, not for the disposal motivation of fast fashion. In the disposal behavior of fast fashion, the high environmental awareness group indicated social friendly disposal and the middle environmental awareness group indicated economical disposal. The result showed significant gender differences towards clothing consumption behavior of fast fashion according to demographic characteristics. Males and females showed significant differences in all purchase motivation factor for fast fashion products. They also showed significant differences in economical disposal towards fast fashion disposal behavior.
\end{abstract}

Key words : clothing consumption behavior(의복소비행동), fast fashion(패스트패션), environmental consciousness(환경 의식)

\section{1. 서 론}

급속한 산업화와 과학기술의 발달은 인간에게 물질문명의 혜 택을 주었지만 풍요로움의 이면에 숨겨진 자원고갈과 환경오염 등의 문제는 인류의 생존기반을 위협하고 있다. 이러한 환경문 제를 해결하기 위하여 인간의 사고와 행동을 환경친화적으로 변화시켜야한다는 주장이 제기되기 시작하면서 다양한 분야에 서 연구가 진행되고 있다. 이에 의류산업 분야에서도 원료의 생 산과정이나 제조 과정에서 발생되는 환경오염 물질을 줄이기 위한 환경친화적인 생산방법에 대한 연구가 꾸준히 진행되어 왔으나, 최근에 급증하는 패스트패션(fast fashion)의 열풍으로 소비과정에서 발생되는 의류폐기물에 대한 환경친화적인 방법 에 대한 연구 중요성도 증대되고 있다.

최근 들어 의류환경시장을 주도하고 있는 패스트패션의 열 풍은 마케팅 환경측면에서도 중요한 부분이기도 하지만 저렴하 고 다양한 디자인의 패스트패션의 등장으로 인한 의류쓰레기량

†Corresponding author; Hyun Ji Lee Tel. +82-31-8033-8028, Fax. +82-51-623-5248

E-mail: hjespoir@naver.com
급증도 간과할 수는 없는 부분이다. 과거에는 의복구입 시 의 복의 기능적인 면을 고려하여 필요한 의복만을 구입하는 반면, 오늘날에는 경제적인 생활 수준 항상과 소비가치관의 변화, 그 리고 빠른 유행의 변화에 따라 의복을 구매하는 횟수가 늘어나 게 되면서 의복의 착용수명은 점차 짧아지게 되고, 심지어 착 용되지도 않은 채 방치되고 폐기되는 의복도 매년 증가되고 있 는 실정이다. 이에 학자들의 우려도 높아지면서 케임브리지 대 학의 보고서(as cited in Lee, 2008)에는 패스트패션을 폐기물 을 양산하는 환경의 적으로 규정하였고, 일부 학자는 티셔츠와 스웨터의 값이 샌드위치 값보다 더 싸게 판매되고 있는 실정이 기에 패스트패션이 환경에 미치는 영향은 패스트푸드 못지않게 심각하다고 주장하였다.

실제 지난 2011년 국내에서 조사된 결과에 따르면, 소비자들 이 1 년간 사들인 의복 중 $50 \sim 70 \%$ 정도를 입지 않는다고 응답 한 소비자가 약 $30 \%$ 였고, $30 \sim 50 \%$ 정도를 입지 않는다고 응 답한 소비자도 $29 \%$ 로 나타났는데, 절반이 넘는 소비자가 돈 주고 구입한 새 옷의 $30 \%$ 이상을 입지 않는다는 의미이다. 이 런 상황에서 패스트패션에 대한 소비자들의 인식과 의복소비행 동에 대한 연구가 필요한 상황이지만, 최근 진행되고 있는 패 
스트패션에 대한 연구는 주로 디자인 분석이나 마켓 전략, 유 통구조에 대한 연구가 주류를 이루고 있다. 따라서 패스트패션 의 문제점으로 볼 수 있는 의류폐기물에 대한 문제점 해결을 위해 패스트패션에 대한 소비자들의 의복소비행동에 대해 살펴 봄으로써 패스트패션 소비자들의 의복소비행동에 대한 이해를 도와 의류폐기물을 줄일 수 있는 방안 모색도 가능할 것으로 사료되므로 연구의 가치가 충분히 있다고 사료된다.

그러므로 본 연구에서는 패스트패션 소비자의 환경인식에 대 하여 알아보고, 환경의식과 인구통계적 특성에 따른 소비행동 에 대해 알아봄으로써 패스트패션 소비행동에 대한 기초 자료 를 제공하고, 이를 통해 소비자들이 패스트패션에서 비롯되는 의류폐기물을 줄여나가는 경제적이고 합리적인 소비행동을 할 수 있는 방안을 모색하는데 의의가 있다.

\section{2. 이론적 배경}

\section{1. 환경의식}

환경의식이란 일상생활 중 환경문제에 대해 인식하며 오염 된 환경을 개선하고 보존하기 위해 자신의 행동을 옮길 수 있 는 생각과 관심을 가리킨다. Henion(1972)은 환경을 의식하는 소비자를 특정제품이나 용역의 구매, 소유, 사용 및 처분 시 환 경에 미치는 영향에 대하여 의식적이고 일관성있는 관심을 가 지고 자신의 가치, 태도, 의식 및 행동에 반영시키는 사람으로 정의하였다.

일반적으로 환경에 대한 관심이 높을수록 환경의식적 소비 행동을 한다고 볼 수 있고 환경에 대한 관심과 환경 의식적 소비행동 사이의 관련성을 인정하였다(Park \& Oh, 2005). Lee (1995)는 소비자의 환경문제와 관련된 의복관리행동과 의류자 원 재활용실태에 관한 조사 연구에서 소비자의 환경문제에 대 한 의식과 행동이 높은 집단일수록 의복 관리행동에서 환경의 식 수행 수준이 높다고 하였고, $\operatorname{Kim}(1995)$ 의 연구결과에서도 소비자의 환경의식에 따라 구매 유형 및 실태에서 유의한 차이 를 보인다고 하였다.

환경의식에 대한 차이는 인구통계적 특성에 따라서도 유의 한 차이가 나타나는데 Choi(1995)의 서울시 주부들의 환경교육 과 환경보전행동에 관한 연구의 결과에서 주부의 연령, 교육, 가계소득, 아파트 거주 여부에 차이를 보였고, Cheon(1999)의 중학생 라이프스타일에 따른 환경문제에 대한 의식과 행동에 관한 연구의 결과에서는 성별, 주거환경, 어머니의 학력에서 유 의한 차이가 있는 것으로 나타났다.

따라서 환경의식과 인구통계적 특성의 차이는 의복소비행동 에도 차이가 나타남을 볼 때 환경의식과 인구통계적 특성에 따 라 패스트패션의 의복소비행동에 차이가 있는지에 대해서 알아 보고자 한다.

\section{2. 패스트패션}

패스트패션이란 외국어 표기신어로 등록되었으며 유행에 따
라서 빨리 바꾸어서 내놓는 옷을 통틀어 이르는 말로 패스트푸 드에 유추하여 만들어낸 말이라 정의하고 있다(National Institute of the Korean Language, 2004). 또한 최신 유행을 즉각 반영한 디자인, 비교적 저렴한 가격, 빠른 상품회전율로 승부하는 패션 또는 패션산업을 뜻하는 말로 정의되고 있다 (Doosan Encyclopedia, 2010).

Chang(2007)은 소비자의 주문사항이나 유행현상을 민첩하게 반영한 제품을 생산하는 방식을 일컫는 것으로 빠른 스피드, 트 렌드에 근접한 기획, 가격 경쟁력이 핵심이며 맥도널드처럼 빠 르고 편리한 패션을 의미하는 맥패션(McFashion), 혹은 한번 쓰고 버리는 디스포져블(disposable)패션이라 설명하고 있고, Lee(2008)는 최신 트렌드에 대한 반응이 빨라 제품주기가 짧고, 통합된 유통형태를 활용하여 다품종 소량생산을 하는 체제라고 설명하였다. Shin(2011)은 고객의 동향에 민감하게 반응할 수 있도록 최신 트렌드에 맞는 다품종의 디자인을 신속하게 생산 하고, 유통과정의 내부통합으로 인한 빠른 상품회전율을 실현 하는 방식을 의미한다고 정의하고 있다. 따라서 패스트패션이 란 최신 유행을 즉각 반영한 다양한 유행상품을 빠른 상품회전 을 통해 내놓는 저렴한 가격의 패션상품이라고 볼 수 있다.

패스트패션에 대한 선행연구를 살펴보면, 패스트패션의 현상 분석에 관한 연구(Ro \& Kim, 2009), 패스트패션의 디자인분석 에 관한 연구(Kim, 2010; Lee, 2010), 패스트패션의 구매행동 에 관한 연구(Kim, 2011; Lee, 2008), 패스트패션 산업의 전 략에 관한 연구(Jang, 2009; Kang \& Sung, 2010) 둥 제품판 매에 영향을 주는 요인과 소비자들의 구매행동에 관한 연구들 이 꾸준히 나타나고 있음을 알 수 있다.

하지만 패스트패션의 선행 연구를 살펴본 결과, 사회문화적 인 현상 분석과 제품의 구매와 관련된 연구가 대부분인 것으로 나타나, 패스트패션으로 야기되는 의류폐기물에 대한 사회적 문 제해결에 도움을 줄 수 있는 방안모색을 위한 소비자들의 의복 소비행동에 대해 살펴볼 가치가 충분히 있다고 사료되므로 본 연구에서는 패스트패션 소비자들의 의복소비행동을 살펴보고 이를 바탕으로 합리적이고 환경친화적인 의복소비행동에 대한 방안제시에 도움을 주고자 한다.

\section{3. 의복소비행동}

2.3.1. 의복구매행동

의복구매행동이란 욕구나 필요에 의해 제품이나 서비스를 획 득하고 사용하는데 있어 구매 전이나 구매과정 중에 나타나는 소비자의 태도와 행동을 포괄적으로 의미하는 것이며, 욕구충 족을 위해 재화나 서비스를 획득, 사용, 처분하는데 수반되는 의사결정과정에서 보이는 정신적, 육체적 행동과정을 의미한다 고 하였다(Lim, 1992). 또한 소비자가 사회문화적인 환경요인 과 개인적 욕구 등의 동기에 따라 제품의 필요성을 문제로 지 각하고, 정보를 탐색한 후 제품을 평가, 선택하는 과정을 거쳐 의복을 구매하는 것을 말한다(An \& Lim, 1999).

의복구매행동의 변수로는 구매동기, 정보원, 의복선택기준, 
점포선택기준, 구매처, 구매빈도, 구매 시기, 구매가격 등이 있 는데 본 연구에서는 환경의식과 패스트패션 소비자들의 구매행 동에 대해 살펴보기 위해 구매동기와 구매횟수, 구매비용을 중 심으로 살펴보고자 한다.

먼저 의복구매동기에 관한 연구를 살펴보면 20대 여성을 대 상으로 한 Lee(1995)의 연구에서는 자기과시성, 유행성, 경제실 리성 등 세 요인으로 분류하였고, 20,30 대 성인남녀를 대상으 로 한 Kang and Hwang(2007)의 연구에서는 쾌락적, 경제적, 점포충성적, 계획적, 편의적, 충동적 성향의 6 개 요인으로 구분 하였으며, 패스트패션에서의 쇼핑성향에 대해 연구한 $\operatorname{Kim}(2011)$ 의 연구에서는 브랜드 충성, 편의지향성, 충동성, 계획실용성, 경제성 등 5 가지 요인으로 구분하였다. 다음으로 의복과 친환 경구매행동에 관한 연구에 대해 살펴보면, Lee and $\operatorname{Kim}(1998)$ 의 연구에서는 의복을 구매할 때는 의복의 품질, 가격, 디자인 뿐 아니라 제조 과정에서 환경문제가 적은 과정을 통해 생산된 섬유로 선택하고, 의복관리에 있어 정리 및 수선과 세탁과정에 서도 환경문제를 적게 일으키고, 의복수명이 길고 재활용이 가 능한지를 고려하여 구매해야 할 것이라고 하였다. 또한 Lee(1997)의 연구에서는 의복을 구입할 때 신경쓰지 않고 싼 것을 사들이게 되면 의복수가 증가하고 의복가치가 약화됨으로 써 의복이 방치되는 경우가 많아진다고 하였으므로 소비자들 이 의복 구매 시 합리적인 구매행동을 하는 것이 중요하다고 하였다.

\subsection{2. 의복사용행동}

의복사용행동은 상품을 구매한 후 계속적으로 이어지는 제 품의 소비 및 사용과정에서의 행동이며, 의복사용행동은 의복 구입 후의 착용, 정리, 세탁 등의 소비행동으로 관리행동과도 같은 의미로 사용되고 있기도 한다.

의복의 사용행동에 대해서 $\mathrm{Yoo}(1996)$ 는 소비자들은 의복 사 용과정에서 의복에 대한 만족도, 소비자의 개인적 특성, 외부적 환경요인 등에 따라 구입된 의복을 자주 착용거나 옷장에 걸어 두기도 한다고 하였고, Lee(1997)는 의복은 물리적 수명이 아 닌 외관적 수명이 짧아지게 되면서, 의복을 폐기하는 경향이 증 대되고 있어 손쉽게 사용하고 나서 버리는 경향으로 변하고 있 다고 하였다. Park(1997)의 연구에서는 사용행동은 소비과정 중 가장 길며, 사용영역에서 환경친화적 정도가 가장 낮게 나타났 다고 했으며, 절약적 사용의 제약요인으로는 번거롭고 불편해 서, 실질적으로 절약이 되지 않아서, 절약방법을 모르기 때문인 것으로 나타났다. Park(2009)의 연구에서는 환경의식에 따라 의복소비행동에 차이가 있는지에 대해 살펴 본 결과 1 년간 구 매한 의복의 방치율은 환경의식에 유의하지 않은 것으로 나타 났다.

\subsection{3. 의복처분행동}

처분행동은 소비행동의 일환으로 처분활동은 제품을 통하여 어떠한 욕구를 충족시킨 뒤 후의 처리행동이라고 정의하였다
(Nicosia \& Mayer, 1976).

의복처분행동에 대한 선행연구를 살펴보면, Shim(1995)은 소 비자 환경태도와 쓰레기 재활용이 의복처분 패턴에 미치는 영 향에 대해 연구하였는데 의복처분패턴을 8 가지 유형으로 나누 어 분석하였고, 소비자의 환경태도는 '자선에 의한 기증', '환 경을 고려한 기증', '환경을 의식한 재사용'에는 정적인 영향을 준 반면, ‘편의지향적 처분'에는 부적인 영향을 미치는 것으로 나타난다고 하였다. 또한 여학생이 남학생보다 환경을 의식하 여 옷을 기증한다거나 팔거나 하는 경향이 더 높았으며, 나이 가 든 학생일수록 자선 또는 환경을 고려하여 옷을 기증하거나 재사용하는 경향이 높다고 하였다. Yoo(1996)의 연구에서는 의 복 폐기의 가장 주된 원인이 새로 구입한 다른 의복때문이었으 며, 그 다음이 유행의 변화, 싫증, 착용 기회의 상실 순으로 나 타났는데, 의복선택에 대한 후회로 인한 의복폐기가 전체 의복 폐기량의 $30 \%$ 를 설명할 정도로 실제적인 원인인 것으로 밝혔 다. Chang(1996)은 사회적 의류처분 행동을 경제적 처분과 이 타적 처분으로 분류하여 인구통계학적 특성, 환경보존 정보 접 촉, 사회책임적 의류소비태도 및 재활용 인센티브와의 관계를 조사하였는데. 그 결과 이타적인 의류처분을 하는 경향이 높은 사람은 교육수준과 연령이 높고, 기혼자이며, 의류재활용에 대 해 호의적이나 유행에 대해서는 비호의적이라 하였다.

$\operatorname{Han}(2009)$ 의 연구에서는 서울거주 남녀를 대상으로 의복처 분행동에 대해 살펴 본 결과, 입지 않는 옷을 그대로 옷장에 보관하는 경우가 많았으며 다음으로 분리수거함에 넣는 것으로 나타났고, 입지 않는 옷을 주변사람들과 교환하여 입거나 중고 판매상이나 인터넷몰을 활용하여 재판매하는 행동은 낮게 나타 났다고 하였다. 또한 의복처분행동에 대한 남녀의 차이는 없는 것으로 나타났지만, 연령에서는 차이가 나타났고 특히 13 17세 미만인 연령층의 경우 옷을 교환하거나 재판매, 분리수거하는 경우가 높게 나타나 친환경적인 처분에 더 관심이 많은 것으로 나타났다.

지금까지 살펴 본 의복처분행동에 관한 연구는 주로 환경의 식에 따른 의복처분행동에 관한 연구가 주류를 이루고 있으므 로 본 연구에서는 패스트패션을 대상으로 하여 의복처분행동에 대해 살펴봄으로써 패스트패션의 의복처분행동에 대한 이해를 돕고자 한다.

\section{3. 연구방법}

\section{1. 연구내용}

본 연구에서는 이론적 연구와 실증적 연구를 병행하였으며, 이론적 연구에서는 패스트패션과 의복소비행동에 대한 이론적 고찰을 진행하였고, 실증적 연구에서는 이론적 연구를 바탕으 로 한 패스트패션 소비자의 의복소비행동에 대해 설문지법을 통하여 연구를 수행하였다. 본 연구에서 수행한 연구문제는 다 음과 같다.

연구문제1: 패스트패션 소비자유형을 환경의식에 따라 분류 
한다.

연구문제2: 환경의식에 따라 패스트패션 소비자의 의복소비 행동에 차이가 있는지 알아본다.

연구문제3: 인구통계적 특성에 따라 패스트패션 소비자의 의 복소비행동에 차이가 있는지 알아본다.

\section{2. 연구방법}

3.2.1. 조사대상 및 자료수집

본 연구의 조사대상은 부산에 거주하는 패스트패션의 구매 경험이 있는 20,30 대 남성과 여성을 대상으로 하였다. 조사대 상의 선정이유는 패스트패션 매장이 서울과 수도권, 광역시에 집중되어져 있으므로 이 지역의 소비자들이 쉽게 접할 수 있어 패스트패션에 대한 관심과 이해가 충분할 것으로 사료되기 때 문이며, 20,30 대는 실제 패스트패션의 주된 소비계층이며, 또 한 인터넷과 기기 사용에 익숙한 계층으로 패스트패션이나 환 경, 의복처분에 대한 정보를 쉽게 접할 수 있는 계층이라는 점 때문이다. 자료수집은 2014년 5월 12일부터 5월 20일까지 실 시하였고, 총 300 부를 배포하여 251 부를 회수하였고, 이 중 응 답이 불충분한 설문지를 제외한 나머지 245 부가 분석에 사용 되었다.

\subsection{2. 척도구성 및 측정방법}

본 연구에서는 환경의식에 따른 패스트패션 소비자의 의복 소비행동에 대해 알아보기 위해 설문지법을 사용한 실증적 연 구를 수행하였고, 설문지 구성은 인구통계적 특성, 환경인식, 패 스트패션에 대한 의복소비행동 항목 등으로 구성하였다. 환경 인식에 대한 문항은 Kim(1995), Park(2009)의 연구에서 패스트 패션 소비자의 구매행동에 대한 인식에 대한 문항은 $\mathrm{Kim}$ (1995)의 연구를 바탕으로 연구자가 수정보완하였으며, 의복사 용행동에 대한 문항은 Park(2009)의 연구에서 의복처분행동에 관한 문항은 Yoo(1996), Chang(1996)의 연구를 참고하여 연구 자가 수정보완하였다.

\subsection{3. 분석방법}

설문지법으로 수집된 자료는 통계프로그램 SPSS 17.0을 이 용하여 통계분석처리 하였다. 본 연구의 가설을 검정하기 전 설 문 항목들의 내적 일관성을 확인하기 위해 Cronboach's Alpha 계수를 이용한 신뢰성 검정을 실시하였고, 환경인식과 패스트 패션 소비자의 의복소비행동에 대한 하위차원을 밝히기 위해 요인분석을 실시하였다. 환경인식과 인구통계특성에 따른 패스 트패션 소비자의 의복소비행동에 대한 차이를 알아보기 위해 t-test와 ANOVA, Duncan Test, $\chi^{2}$ 검증을 실시하였다.

\subsection{4. 조사대상자의 인구통계적 특성}

조사대상자의 인구통계적 특성을 살펴보면(Table 1), 남성이 107 명(43.7\%), 여성이 138 명(56.3\%)이었으며 20대는 130 명 (53.1\%), 30대는 115 명 $(46.9 \%)$ 이었다. 학력은 고등학교 졸업
Table 1. The demographic characteristics of participants $(\mathrm{N}=245)$

\begin{tabular}{ccc}
\hline Variable & Division & $\mathrm{N}(\%)$ \\
\hline \multirow{2}{*}{ Gender } & Male & $107(43.7)$ \\
& Female & $138(56.3)$ \\
\hline \multirow{2}{*}{ Age } & 20 's & $130(53.1)$ \\
& 30 's & $115(46.9)$ \\
\hline \multirow{2}{*}{ Education } & High school & $96(39.2)$ \\
& College or University & $121(49.4)$ \\
& Graduate school & $28(11.4)$ \\
\hline \multirow{3}{*}{ Occupation } & Student & $58(23.7)$ \\
& Professionals & $51(20.8)$ \\
& Office job & $65(26.5)$ \\
& Business & $35(14.3)$ \\
Average & Others & $36(14.7)$ \\
monthly & Less than 2,000,000 & $96(39.2)$ \\
income(won) & 2,000,000 4,000,000 & $92(37.6)$ \\
& More than 6,000,000 & $40(16.3)$ \\
\hline
\end{tabular}

이하가 96명(39.2\%), 대학교 졸업 이하는 121 명(49.4\%), 대학 원 졸업 이상이 28 명 $(11.4 \%)$ 이었다. 직업은 학생이 58 명 (23.7\%), 전문직은 51명(20.8\%), 사무직이 65명(26.5\%), 자영업 이 35 명(14.3\%), 기타가 36 명 $(14.7 \%)$ 이었다. 월평균 소득은 200 만원 미만이 96 명(39.2\%), 200만원 0이상 400만원 이하가 92명(37.6\%), 400만원 이상 600만원 이하가 40명(16.3\%), 600 만원 이상이 17 명 $(6.9 \%)$ 이었다.

\section{4. 결과 및 논의}

\section{1. 패스트패션 소비자의 환경의식에 따른 분류}

\subsection{1. 환경의식집단분류}

환경의식에 따른 패스트패션 소비자의 의복소비행동에 대해 알아보기 앞서 환경의식에 따른 패스트패션 소비자의 유형을 분석하기 위해 측정한 변수는 Table 2 와 같고 환경의식에 따른 소비자집단유형분류는 측정된 변수의 평균점수와 표준편차를 기준으로 점수가 낮은 집단(M-SD/2), 중간 집단(M-SD/2 $\mathrm{M}+\mathrm{SD} / 2)$, 높은 집단(M+SD/2)으로 분류하였다.

\subsection{2. 인구통계적 특성에 따른 환경의식집단분류}

다음으로 인구통계적 특성에 따른 환경인식에 대한 차이를 알아보기 위해 $\chi^{2}$ 검정을 실시하였고 그 결과는 Table 3 과 같다. 결과를 살펴보면 성별, 연령, 직업, 월평균수입에 있어서는 환 경의식 집단 간 차이가 나타나지 않았으나 학력에 따라서는 유 의한 차이가 있는 것으로 나타났다. 이는 Choi(1995)의 연구에 서 환경의식과 환경행동에 주부의 학력이 유의한 차이를 보이 는 것과 일치하지만 주부의 학력이 높아질수록 환경의식이 높 아진다는 결론과는 다소 차이가 있음을 알 수 있다. 본 연구의 결과에서는 대학원졸업 학력집단에서 환경의식이 높은 집단이 $28.6 \%$ 인데 비해 대학교졸업의 학력집단에서는 $36.4 \%$, 고등학 
Table 2. The measurement variables of environmental consciousness

\begin{tabular}{clrr}
\hline Factor & \multicolumn{1}{c}{ Items } & Mean & S.D. \\
\hline & I know that soil contamination due to the pesticides used in cotton cultivation. & 2.35 & .92 \\
Environmental & I know the harmful chemicals used for human health on the environment from the clothing & 3.25 & 1.09 \\
consciousness & production process. & & \\
& I know about the environmental problems that occur in the course of disposal of synthetic fibers. & 2.78 & 1.11 \\
& I know that clothing dyed with natural dyestuff. & 2.92 & 1.22 \\
\hline & \multicolumn{1}{c}{ Total } & 2.83 & 1.085 \\
\hline
\end{tabular}

Table 3. The demographic characteristics of environmental consciousness groups

\begin{tabular}{|c|c|c|c|c|c|}
\hline Variable & Division & $\begin{array}{l}\text { High } \\
(\mathrm{N}=72)\end{array}$ & $\begin{array}{l}\text { Middle } \\
(\mathrm{N}=98)\end{array}$ & $\begin{array}{l}\text { Low } \\
(\mathrm{N}=75)\end{array}$ & $\begin{array}{c}\text { Total } \\
(\mathrm{N}=245)\end{array}$ \\
\hline \multirow{2}{*}{ Gender } & Male & $31(29.0)$ & $41(38.3)$ & $35(32.7)$ & $107(43.7)$ \\
\hline & Female & $41(29.7)$ & $57(41.3)$ & $40(29.0)$ & $138(56.3)$ \\
\hline \multicolumn{6}{|c|}{$\chi^{2}=0.407 d f=2$} \\
\hline \multirow{2}{*}{ Age } & 20 's & $33(25.4)$ & $55(42.3)$ & $42(32.3)$ & $130(53.1)$ \\
\hline & 30 's & $39(33.9)$ & $43(39.4)$ & $33(28.7)$ & $115(46.9)$ \\
\hline \multicolumn{6}{|c|}{$\chi^{2}=2.137 d f=2$} \\
\hline \multirow{3}{*}{ Education } & High school & $20(20.8)$ & $40(41.7)$ & $36(37.5)$ & $96(39.2)$ \\
\hline & College or University & $44(36.4)$ & $46(38.0)$ & $31(25.6)$ & $121(49.4)$ \\
\hline & Graduate school & $8(28.6)$ & $12(42.8)$ & $8(28.6)$ & $28(11.4)$ \\
\hline \multicolumn{6}{|c|}{$\chi^{2}=7.073^{*} d f=4$} \\
\hline \multirow{5}{*}{ Occupation } & Student & 19(32.7) & $23(39.7)$ & $16(27.6)$ & $58(23.7)$ \\
\hline & Professionals & $21(41.2)$ & $19(37.3)$ & $11(21.5)$ & $51(20.8)$ \\
\hline & Office job & $12(18.5)$ & $30(46.1)$ & $23(35.4)$ & $65(26.5)$ \\
\hline & Business & $9(25.7)$ & 14(40.0) & $12(34.3)$ & $35(14.3)$ \\
\hline & Others & $1(30.6)$ & $12(33.3)$ & $13(36.1)$ & $36(14.7)$ \\
\hline \multicolumn{6}{|c|}{$\chi^{2}=9.109 d f=8$} \\
\hline Average & Less than $2,000,000$ & $24(25.0)$ & $42(43.8)$ & $30(31.2)$ & $96(39.2)$ \\
\hline monthly & $2,000,000 \sim 4,000,000$ & $31(33.7)$ & $34(37.0)$ & $27(29.3)$ & $92(37.6)$ \\
\hline income & $4,000,000 \sim 6,000,000$ & $12(30.0)$ & $15(37.5)$ & $13(32.5)$ & $40(16.3)$ \\
\hline (won) & More than $6,000,000$ & $5(29.4)$ & $7(41.2)$ & $5(29.4)$ & $17(6.9)$ \\
\hline \multicolumn{6}{|c|}{$\chi^{2}=2.044 d f=6$} \\
\hline
\end{tabular}

교졸업 집단은 $20.8 \%$ 로 나타나 학력이 높을수록 환경의식이 높다고 보기에는 다소 무리가 있는 것으로 사료되기 때문이다. 이는 고등학교 졸업자에 비해 대학교와 대학원 졸업자에서 환 경의식이 비교적 높게 나타나고 있지만 대학원 졸업자의 연구 대상 수가 대학교 졸업자 수에 비해 비교적 낮게 나타남으로써 두 집단간의 차이를 뚜렷하게 보여주지 못한 결과로 사료된다.

\section{2. 환경의식에 따른 패스트패션 소비자의 의복소비행동}

\subsection{1. 의복구매행동}

4.2.1.1. 패스트패션 소비자의 의복구매행동의 하위차원

패스트패션 소비자의 의복구매행동에 대한 하위차원을 알아 보기 위해 요인분석을 실시한 결과는 Table 4에서 보여지는 바 와 같이 총 3 가지로 나타났으며, 쾌락성 추구, 실용성 추구, 유 행성 추구 등으로 명명하였다. 각 요인들의 신뢰도는 모두 0.70 이상으로 높았으며 세 가지 요인에 대한 설명력은 $70.229 \%$ 였
다. 이는 Lee(1995)의 연구에서는 나타난 유행성, 경제실리성의 요인과 일치하였고, Kang and Hwang(2007)의 연구에서 나타 난 쾌락적, 경제적 요인과 일치하였으며 $\operatorname{Kim}(2011)$ 의 연구에서 나타난 계획실용성, 경제성 요인과도 일치함을 알 수 있었다.

4.2.1.2. 환경의식에 따른 패스트패션 소비자의 의복구매행동 환경의식 집단별 패스트패션 소비자의 의복구매행동 차이를 알아보기 위해서 소비자들의 구매동기, 일년간 패스트패션 구 매비용, 한달간 패스트패션 구매횟수 등에 대해서 살펴보았다. 먼저 구매 시 추구혜택을 알아보기 위해서 ANOVA를 실시하 였고 유의한 차이가 있는 변인들에 대해서는 Duncan Test를 실시하였는데 그 결과는 Table 5와 같다. 그 결과 앞서 분석한 구매동기의 세요인 중 쾌락추구요인만 환경의식집단별 차이를 보였으며 환경의식이 낮은 집단일수록 쾌락적 구매를 추구하는 반면 환경의식이 높을수록 쾌락적 구매추구가 낮음을 보였다. 
Table 4. The result of factor analsys for purchase motivation of fast fashion consumer

\begin{tabular}{|c|c|c|c|c|}
\hline Factor & Items & $\begin{array}{l}\text { Factor } \\
\text { loading }\end{array}$ & $\begin{array}{c}\text { Eigen value } \\
\text { (Variance eaplained }(\%) \text { ) }\end{array}$ & $\begin{array}{c}\text { Cronbach' } \\
\alpha\end{array}$ \\
\hline $\begin{array}{l}\text { Hedonic } \\
\text { pursuit }\end{array}$ & $\begin{array}{l}\text { For relaxation. } \\
\text { To feel fun just watching. } \\
\text { To feel pleasure. }\end{array}$ & $\begin{array}{l}.901 \\
.892 \\
.845\end{array}$ & $\begin{array}{c}2.966 \\
(29.661)\end{array}$ & .861 \\
\hline $\begin{array}{l}\text { Practical } \\
\text { pursuit }\end{array}$ & $\begin{array}{l}\text { Because of purchase of necessary clothes. } \\
\text { Because of low price compared to other products. } \\
\text { Because of good quality. } \\
\text { Because of a lot of discounts. }\end{array}$ & $\begin{array}{l}.816 \\
.774 \\
.739 \\
.731\end{array}$ & $\begin{array}{c}2.250 \\
(22.497)\end{array}$ & .772 \\
\hline $\begin{array}{l}\text { Trend } \\
\text { pursuit }\end{array}$ & $\begin{array}{l}\text { To follow trend. } \\
\text { To follow TV and magazin style. } \\
\text { To follow the style of others. }\end{array}$ & $\begin{array}{l}.832 \\
.810 \\
.725\end{array}$ & $\begin{array}{c}1.807 \\
(18.072)\end{array}$ & .706 \\
\hline
\end{tabular}

Table 5. The differences of purchase motivation on fast fashion among segmented group

\begin{tabular}{|c|c|c|c|c|c|c|c|c|}
\hline \multirow{2}{*}{ Variable } & \multirow[t]{2}{*}{ Group } & \multicolumn{2}{|c|}{$\begin{array}{l}\text { High } \\
(\mathrm{N}=72)\end{array}$} & \multicolumn{2}{|c|}{$\begin{array}{l}\text { Middle } \\
(\mathrm{N}=98)\end{array}$} & \multicolumn{2}{|c|}{$\begin{array}{c}\text { Low } \\
(\mathrm{N}=75)\end{array}$} & \multirow[t]{2}{*}{$\mathrm{F}$} \\
\hline & & M & S.D. & $\mathrm{M}$ & S.D. & M & S.D. & \\
\hline \multirow{3}{*}{ Purchase motivation } & Hedonic pursuit & 2.73 & $.78 \mathrm{a}$ & 3.15 & $.65 b$ & 3.26 & $.71 \mathrm{~b}$ & \multirow{3}{*}{$8.06^{* * *}$} \\
\hline & Practical pursuit & 3.05 & .76 & 3.03 & .67 & 2.93 & .69 & \\
\hline & Trend pursuit & 2.29 & .77 & 2.26 & .71 & 2.23 & .68 & \\
\hline
\end{tabular}

${ }^{*} p<.05, \quad{ }^{* *} p<.01, \quad{ }^{* * *} p<.001$, Duncan $\mathrm{a}<\mathrm{b}$

이는 환경의식이 낮은 집단보다 환경의식이 높은 집단에서 의 복을 계획구매를 한다는 $\operatorname{Kim}(1995)$ 의 연구결과와 비슷한 맥락 으로 볼 수 있다. 따라서 패스트패션 구매 시에도 환경의식에 따라 구매동기가 달라짐을 알 수 있었다.

다음은 일년간 패스트패션을 구매하는데 지출하는 비용과 한 달간 패스트패션을 구매하는 횟수에 대해 환경의식집단별 차이 를 살펴본 결과로(Table 6), 집단 간 차이가 유의하지 않은 것 으로 나타나 환경의식에 따른 패스트패션 구매비용과 구매횟수 에 차이가 없음을 알 수 있었다. 이는 Han(2009)과 Park(2009) 의 연구에서 친환경의식에 따른 친환경 의복구매행동이 월평균 의복비와 의복구매횟수에 따라 환경의식 집단별 유의한 차이가 있다는 결과와 다르게 나타났다. 또한 $\operatorname{Han}(2009)$ 과 $\operatorname{Park}(2009)$
의 연구에서는 월평균 의복비와 의복구매횟수가 낮은 것은 계 획적으로 의복을 구매함으로써 의복폐기물량을 줄 일 수 있어 환경에 도움을 줄 수 있으므로 환경행동이 높은 것으로 볼 수 있다고 하였는데, 본 연구에서는 패스트패션 연평균 의복비와 월평균 구매횟수가 환경의식과는 유의하지 않은 것으로 나타나 패스트패션의 의복비지출과 구매횟수에 영향을 주는 원인들을 다각도로 생각해 볼 필요가 있다고 사료된다. 예를 들면 소비 자의 경제적 여건에 따라 의복비와 구매횟수에 차이가 생길 수 있으며, 패스트패션에 대한 선호도에 따라서도 차이가 생길 수 있으므로 패스트패션의 구매비용과 구매횟수를 환경의식만으로 해석하기에는 다소 무리가 있는 것으로 판단되기에 다양한 요 인을 통한 분석이 향후 고려되어져야 할 것으로 사료된다.

Table 6. The differences of purchase expenses and purchase frequency of fast fashion products among segmented group

\begin{tabular}{|c|c|c|c|c|c|}
\hline Variable & Group & $\begin{array}{l}\text { High } \\
(\mathrm{N}=72)\end{array}$ & $\begin{array}{l}\text { Middle } \\
(\mathrm{N}=98)\end{array}$ & $\begin{array}{l}\text { Low } \\
(\mathrm{N}=75)\end{array}$ & $\begin{array}{c}\text { Total } \\
(\mathrm{N}=245)\end{array}$ \\
\hline \multirow{5}{*}{$\begin{array}{l}\text { Purchase } \\
\text { expenses } \\
\text { for a year } \\
\text { (won) }\end{array}$} & Less than 200,000 & $35(34.0)$ & $43(41.7)$ & $25(24.3)$ & $103(42.0)$ \\
\hline & $200,000 \sim 400,000$ & $24(24.7)$ & $37(38.1)$ & $36(37.2)$ & $97(39.6)$ \\
\hline & $400,000 \sim 600,000$ & $11(30.5)$ & $15(41.7)$ & $10(27.8)$ & $36(14.7)$ \\
\hline & More than 600,000 & $2(22.2)$ & $3(33.3)$ & $4(44.5)$ & $9(3.7)$ \\
\hline & & \multicolumn{4}{|c|}{$\chi^{2}=5.058 d f=6$} \\
\hline \multirow{5}{*}{$\begin{array}{c}\text { Purchase } \\
\text { frequency } \\
\text { per a month }\end{array}$} & More than $2 \sim 3$ times a month & $2(18.2)$ & $4(36.4)$ & $5(45.4)$ & $11(0.04)$ \\
\hline & 2 3 times a month & $31(34.8)$ & $38(42.6)$ & $20(22.6)$ & $89(36.3)$ \\
\hline & Once a month & $31(28.2)$ & $45(40.9)$ & $34(30.9)$ & $110(44.9)$ \\
\hline & Once $2 \sim 3$ month & $8(22.9)$ & $11(31.4)$ & $16(45.7)$ & $35(14.3)$ \\
\hline & & \multicolumn{4}{|c|}{$\chi^{2}=8.146 d f=6$} \\
\hline
\end{tabular}


Table 7. The differences of neglect clothing rate of fast fashion among segmented group

\begin{tabular}{|c|c|c|c|c|c|}
\hline Variable & Group & $\begin{array}{l}\text { High } \\
(\mathrm{N}=72)\end{array}$ & $\begin{array}{l}\text { Middle } \\
(\mathrm{N}=98)\end{array}$ & $\begin{array}{l}\text { Low } \\
(\mathrm{N}=75)\end{array}$ & $\begin{array}{c}\text { Total } \\
(\mathrm{N}=245)\end{array}$ \\
\hline & Less than $30 \%$ & $38(37.6)$ & $41(40.6)$ & $22(21.8)$ & $101(41.2)$ \\
\hline Neglect & $30 \% \sim 50 \%$ & $26(28.3)$ & $35(38.0)$ & $31(33.7)$ & $92(37.5)$ \\
\hline clothing & $50 \% \sim 70 \%$ & $5(16.1)$ & $15(48.4)$ & $11(35.5)$ & $31(12.7)$ \\
\hline rate & $70 \% \sim 90 \%$ & $2(14.3)$ & $4(28.6)$ & $8(57.1)$ & $14(5.7)$ \\
\hline & More than $90 \%$ & $2(14.2)$ & $3(42.9)$ & $3(42.9)$ & $7(2.9)$ \\
\hline \multicolumn{6}{|c|}{$\chi^{2}=31.867^{* * *} d f=8$} \\
\hline
\end{tabular}

\subsection{2. 의복사용행동}

환경의식 집단에 따른 패스트패션 의복사용행동에 대해 유 의한 차이가 있는지 알아보기 위해 $\chi^{2}$ 검정을 실시한 결과는 Table 7과 같고 환경의식 집단별 유의한 차이가 있는 것으로 나타났다. 특히 환경의식이 높은 집단의 경우 의복방치율이 $30 \%$ 미만인 집단이 $37.6 \%$ 로 가장 높게 나타난 반면, 환경의식 이 낮은 집단에서는 의복방치율이 $70 \%$ 이상인 집단이 $57.1 \%$, $90 \%$ 이상이 집단이 42.9 로 높은 비율로 나타났다. 따라서 환 경의식이 높을수록 의복방치율은 낮아짐을 알 수 있었는데 이 는 패스트패션의 저렴한 가격으로 인해 계획적이지 못한 의복 사용행동을 하고 있는 것으로 볼 때 소비자들의 합리적인 의복 사용행동이 요구됨을 유추해 볼 수 있다. 이는 Park(2009)의 연구에서 환경의식이 의복방치율에 유의한 차이를 나타내지 않 는다는 결과와는 다르게 나타난 것으로 $\operatorname{Park(2009)}$ 의 연구에서 는 의복에 쉽게 싫증을 낼 수 있는 10 20대를 대상으로 하였 기 때문에 환경의식과 의복방치율에 차이가 없었다고 해석하고 있었다. 따라서 환경의식에 따른 의복 방치율에 따른 집단 간 차이는 연령대에 따라 달라질 수 있음을 알 수 있었다. 그러므 로 의복방치율에 대한 해석을 환경의식만으로 해석하기에는 다 소 무리가 있으므로 향후 다양한 변수 도입을 통해 좀 더 포 괄적인 해석을 할 필요가 있다고 사료된다.

\subsection{3. 의복처분행동}

4.2.3.1. 패스트패션 소비자의 의복처분행동의 하위차원
패스트패션의 의복처분행동에 대한 하위차원을 알아보기 위 해 요인분석을 실시한 결과는 Table 8과 같이 나타났으며, 패 스트패션의 처분행동에 대한 하위차원은 사회친화적 처분, 경 제적 처분, 편의적 처분 등 총 3 가지로 나타났다. 사회친화적 처분에는 이웃에 나눠주거나 바자회 판매, 자선단체 기부 등의 내용이 포함되었고, 경제적 처분에는 리폼과 중고물품으로 파 는 내용을 포함하였으며, 편의적 처분에는 옷장에 방치하거나 쓰레기통에 버린다는 항목을 포함하였다. 각 요인들의 신뢰도 는 모두 0.60 이상으로 나타났으며 세 가지 요인에 대한 설명 력은 $65.679 \%$ 였다. 이는 $\operatorname{Shim}(1995)$ 의 연구에서 밝힌 의복처 분패턴 중 자선에 의한 기증과 환경을 고려한 기증에 해당하는 사회친화적 처분과 편의지향적 처분과 일치함을 알 수 있었고, Chang(1996)의 연구에서 의류처분 행동을 경제적 처분과 사회 친화적 처분인 이타적 처분으로 분류한 것과 같이 나타남을 알 수 있었다.

다음으로 패스트패션의 처분행동에 있어 처분동기에 대한 하 위차원을 알아보기 위해 요인분석을 실시한 결과는 Table 9와 같이 나타났으며, 추출된 세 가지 요인에 대해 싫증, 변형, 부 적합요인으로 명명하였고, 각 요인들의 신뢰도는 모두 0.67 이 상으로 높게 나타났으며 세 가지 요인에 대한 설명력은 $65.132 \%$ 였다.

4.2.3.2. 환경의식에 따른 패스트패션 소비자의 처분행동 환경의식에 따른 패스트패션 소비자의 처분행동의 차이를 알

Table 8. The result of factor analysis for disposal behavior of fast fashion consumer

\begin{tabular}{|c|c|c|c|c|}
\hline Factor & Items & $\begin{array}{l}\text { Factor } \\
\text { loading }\end{array}$ & $\begin{array}{c}\text { Eigen value } \\
\text { (Variance eaplained }(\%) \text { ) }\end{array}$ & $\begin{array}{c}\text { Cronbach' } \\
\alpha\end{array}$ \\
\hline \multirow{4}{*}{$\begin{array}{l}\text { Social-friendly } \\
\text { disposal }\end{array}$} & Hand out unused clothes to neighbors. & .774 & & \multirow{4}{*}{.736} \\
\hline & Sell unused clothes in bazaars. & .761 & 3.339 & \\
\hline & Donate unused clothes to charity. & .750 & $(37.100)$ & \\
\hline & Hand out unused clothes to relatives. & .577 & & \\
\hline \multirow{3}{*}{$\begin{array}{l}\text { Economic } \\
\text { disposal }\end{array}$} & Reform and wear. & .897 & \multirow{3}{*}{$\begin{array}{c}1.472 \\
(16.358)\end{array}$} & \multirow{3}{*}{.778} \\
\hline & Reform other purposes. & .893 & & \\
\hline & Sell unused clothes in the flea market and used site. & .575 & & \\
\hline \multirow{2}{*}{$\begin{array}{l}\text { Opportunistic } \\
\text { disposal }\end{array}$} & Leave in the closet. & .861 & 1.100 & \multirow{2}{*}{.601} \\
\hline & Disposal to waste box. & .539 & $(12.221)$ & \\
\hline
\end{tabular}


Table 9. The result of factor analsys for disposal motivation of fast fashion consumer

\begin{tabular}{|c|c|c|c|c|}
\hline Factor & Items & $\begin{array}{l}\text { Factor } \\
\text { loading }\end{array}$ & $\begin{array}{c}\text { Eigen value } \\
\text { (Variance eaplained (\%)) }\end{array}$ & $\begin{array}{c}\text { Cronbach' } \\
\alpha\end{array}$ \\
\hline \multirow{4}{*}{ Boredom } & Because of past trend. & .842 & \multirow{4}{*}{3.512} & \multirow{4}{*}{.771} \\
\hline & Because of many same design clothes. & .823 & & \\
\hline & Because of too short fashion cycle. & .766 & & \\
\hline & Because of boredom & .540 & & \\
\hline \multirow{2}{*}{ Strain } & Because of discoloration. & .896 & \multirow{2}{*}{2.187} & \multirow{2}{*}{.697} \\
\hline & Because of stain of clothing form. & .885 & & \\
\hline \multirow{2}{*}{ Inadequate } & Because of not fit for me. & .810 & \multirow{2}{*}{1.466} & \multirow{2}{*}{.669} \\
\hline & Because of not fit my other clothes. & .749 & & \\
\hline
\end{tabular}

Table 10. The differences of disposal behavior and motivation of fast fashion among segmented group

\begin{tabular}{|c|c|c|c|c|c|c|c|c|}
\hline \multirow{2}{*}{\multicolumn{2}{|c|}{$\overbrace{\text { Variable }}$}} & \multicolumn{2}{|c|}{$\begin{array}{l}\text { High } \\
(\mathrm{N}=72)\end{array}$} & \multicolumn{2}{|c|}{$\begin{array}{l}\text { Middle } \\
(\mathrm{N}=98)\end{array}$} & \multicolumn{2}{|c|}{$\begin{array}{l}\text { Low } \\
(\mathrm{N}=75)\end{array}$} & \multirow[t]{2}{*}{$\mathrm{F}$} \\
\hline & & $\mathrm{M}$ & S.D. & $\mathrm{M}$ & S.D. & M & S.D. & \\
\hline \multirow{3}{*}{$\begin{array}{l}\text { Disposal } \\
\text { behavior }\end{array}$} & Social-friendly disposal & 3.32 & $0.69 \mathrm{a}$ & 3.62 & $0.62 \mathrm{~b}$ & 2.36 & $0.68 \mathrm{a}$ & \multirow{3}{*}{$\begin{array}{c}10.113^{* * * *} \\
6.048^{* *}\end{array}$} \\
\hline & Economic disposal & 2.55 & $0.69 \mathrm{a}$ & 2.35 & $0.61 b$ & 2.27 & $0.74 \mathrm{a}$ & \\
\hline & Opportunistic disposal & 2.84 & 0.63 & 3.08 & 0.62 & 2.99 & 0.62 & \\
\hline \multirow{3}{*}{$\begin{array}{l}\text { Disposal } \\
\text { motivation }\end{array}$} & Boredom & 3.02 & 0.57 & 3.02 & 0.64 & 2.99 & 0.75 & 1.465 \\
\hline & Stain & 2.55 & 0.61 & 2.34 & 0.65 & 2.31 & 0.72 & 1.436 \\
\hline & Inadequate & 3.14 & 0.62 & 3.07 & 0.63 & 3.15 & 0.57 & 0.886 \\
\hline
\end{tabular}

${ }^{*} p<.05, \quad{ }^{* *} p<.01, \quad{ }^{* * *} p<.001$, Duncan $\mathrm{a}<\mathrm{b}$

아보기 ANOVA와 Duncan Test를 실시한 결과는 Table 10과 같고 처분행동에는 집단 간 유의한 차이가 있고 처분동기에 대 해서는 집단 간 차이가 없는 것으로 나타났다. 처분행동에서 는 환경의식이 높은 집단과 중간집단에서 사회친화적 처분과 경 제적 처분을 하는 것으로 나타나 환경의식이 높은 집단이 의복 재활용을 한다는 Park(2009)의 연구결과와 일치함을 알 수 있 었다.

\section{3. 인구통계적 특성에 따른 패스트패션 소비자의 의복소비} 행동

다음은 인구통계적 특성에 따른 패스트패션의 의복소비행동 에 대해서 알아보았는데 분석결과 인구통계적 특성 중 의복소 비행동에 차이를 보이는 변인은 성별인 것으로 나타났다. 따라 서 성별에 따른 의복소비행동에 대해 살펴보도록 하겠다.

\subsection{1. 인구통계적 특성에 따른 의복구매행동}

인구통계적 특성에 따른 패스트패션에 대한 의복구매행동 중 구매동기에 대한 차이에 대해 살펴 본 결과는 Table 11과 같 고, 쾌락성 추구, 실용성추구, 유행성 추구 세요인 모두 집단 간 차이를 보이는 것으로 나타났다. 특히 쾌락성 요인에서는 남 성집단은 평균 3.36 인데 비해 여성 집단의 경우 평균 4.03 의 높은 점수를 보여 패스트패션 구매 시 쾌락성 추구요인이 크게 작용함을 알 수 있었고 이로 인한 의복방치율이나 처분에도 영 향을 미칠 것으로 사료되었다.
Table 11. The differences of purchase motivation of fast fashion by gender

\begin{tabular}{|c|c|c|c|c|c|}
\hline \multirow{2}{*}{ Gender } & \multicolumn{2}{|c|}{ Male $(\mathrm{N}=107)$} & \multicolumn{2}{|c|}{ Female $(\mathrm{N}=138)$} & \multirow{2}{*}{$\mathrm{t}$} \\
\hline & $M$ & S.D. & $\mathrm{M}$ & S.D. & \\
\hline Hedonic pursuit & 3.36 & .92 & 4.03 & .73 & $-6.33^{* *}$ \\
\hline Practical pursuit & 3.40 & .93 & 3.54 & .75 & $-1.28^{* *}$ \\
\hline Trend pursuit & 2.84 & .93 & 2.94 & .66 & $-1.00^{* * *}$ \\
\hline
\end{tabular}

\subsection{2. 인구통계적 특성에 따른 사용행동}

성별에 따른 의복사용행동에 대한 차이를 알아보기 위해 $\chi^{2}$ 검정을 실시한 결과(Table 12), 의복방치율에는 유의한 차이가 있는 것으로 나타났다. 남성의 경우에는 의복방치율 $30 \%$ 미만

Table 12. The differences of neglect clothing rate of fast fashion by gender

\begin{tabular}{ccccc}
\hline Variable Division & Group & $\begin{array}{c}\text { Male } \\
(\mathrm{N}=107)\end{array}$ & $\begin{array}{c}\text { Female } \\
(\mathrm{N}=138)\end{array}$ & $\begin{array}{c}\text { Total } \\
(\mathrm{N}=245)\end{array}$ \\
\hline \multirow{3}{*}{ Neglect } & Less than $30 \%$ & $57(56.4)$ & $44(43.6)$ & $101(41.2)$ \\
clothing & $30 \% \sim 50 \%$ & $36(39.1)$ & $56(60.9)$ & $92(37.5)$ \\
rate & $50 \% \sim 70 \%$ & $7(22.6)$ & $24(77.4)$ & $31(12.7)$ \\
& $70 \% \sim 90 \%$ & $5(7)$ & $9(64.3)$ & $14(5.7)$ \\
& More than $90 \%$ & $2(28.6)$ & $5(71.4)$ & $7(2.9)$ \\
\hline \multicolumn{5}{c}{$\chi^{2}=14.073^{* *} d f=4$} \\
$p<.01$
\end{tabular}


이 $56.4 \%$ 로 나타난 반면 여성의 경우 $50 \sim 70 \%$ 가 $77.4 \%$ 로 나 타나 남성에 비해 의복방치율이 높은 것으로 나타났는데 이는 앞서 살펴본 패스트패션 구매행동에서 여성이 남성에 비해 쾌 락적 구매를 많이 하는 결과로 유추해 볼 때 패스트패션 구매 시 여성의 합리적인 구매가 필요한 것으로 사료된다.

\subsection{3. 인구통계적 특성에 따른 의복처분행동}

다음으로 패스트패션에 대한 의복처분행동에 대한 인구통계 적 특성에 따른 차이를 살펴 본 결과(Table 13). 경제적 처분 에서 남성과 여성이 차이를 보이는 것으로 나타났다. 이는 $\operatorname{Shim}(1995)$ 의 연구에서 여학생이 남학생보다 옷을 기증한다거 나 팔거나 하는 경향이 더 높게 나타난 결과와 비교해볼 수 있는데, 선행연구에서는 여성이 환경의식이 높으므로 경제적 처 분을 한다고 해석하였으나 본 연구에서는 여성은 패스트패션 구매 시 쾌락적 구매를 하고 의복방치율도 높게 나타나 환경의 식이 높다고 볼 수 없으므로 선행연구의 결과와 일치한다고 볼 수 없다. 따라서 여성과 남성의 경제적 처분행동에 차이가 있 는 결과는 여성이 남성에 비해 리폼을 하거나 중고사이트에 의 복을 판매하는 경제적 처분에 대한 관심이 많기 때문인 것으로 사료된다. 또한 성별에 따른 차이는 없지만 처분행동 세 요인 중 점수가 가장 높게 나타난 편의적 처분의 점수가 남성 3.07 , 여성 3.14로 높게 나타나 아직도 의복처분행동의 높은 부분을 차지하고 있음을 알 수 있었다. 이는 $\operatorname{Han}(2009)$ 의 연구에서는 서울거주 남녀를 대상으로 의복처분행동에서 대해서 살펴 본 결과 남녀의 차이가 없었고, 처분행동의 요인 중 입지 않는 옷 을 그대로 옷장에 보관하거나 분리수거함에 넣는 편의적 처분 이 높게 나타난 결과와 일치함을 알 수 있다.

다음으로 패스트패션에 대한 의복처분동기에 대한 인구통계 적 특성에 따른 차이를 살펴 본 결과는 Table 13 과 같고 남성 과 여성은 싫증변인에서 유의한 차이를 보이는 것으로 나타났

Table 13. The differences of disposal behavior of fast fashion by gender

\begin{tabular}{|c|c|c|c|c|c|}
\hline \multirow{2}{*}{$\begin{array}{l}\text { Disposal } \\
\text { behavior }\end{array}$} & \multicolumn{2}{|c|}{ Male $(\mathrm{N}=107)$} & \multicolumn{2}{|c|}{ Female $(\mathrm{N}=138)$} & \multirow{2}{*}{ t-value } \\
\hline & M & S.D. & M & S.D. & \\
\hline Social-friendly disposal & 2.06 & .64 & 1.93 & .66 & 1.55 \\
\hline Economic disposal & 2.82 & .97 & 2.93 & .71 & $-1.04^{* * *}$ \\
\hline Opportunistic disposal & 3.07 & .70 & 3.14 & .65 & -1.00 \\
\hline
\end{tabular}

Table 14. The differences of disposal motivation of fast fashion by gender

\begin{tabular}{|c|c|c|c|c|c|}
\hline \multirow{2}{*}{ Gender } & \multicolumn{2}{|c|}{ Male $(\mathrm{N}=107)$} & \multicolumn{2}{|c|}{ Female $(\mathrm{N}=138)$} & \multirow{2}{*}{ t-value } \\
\hline & M & S.D. & M & S.D. & \\
\hline Boredom & 2.47 & .82 & 2.68 & .68 & $-2.21^{* *}$ \\
\hline Stain & 3.00 & .98 & 2.82 & .86 & 1.55 \\
\hline Inadequate & 2.65 & .79 & 2.83 & .76 & -1.75 \\
\hline
\end{tabular}

다. 또한 집단 간 차이를 보이지는 않지만 싫증요인보다 변형 이나 부적합요인에서 평균이 높게 나타났는데 이는 Yoo(1996) 의 연구에서는 의복 폐기의 가장 주된 원인이 새로 구입한 의 복으로 인한 싫증때문이었으며, 그 다음이 유행의 변화, 싫증, 착용 기회의 상실 순으로 나타난 것과 다소 차이를 보이는 것 으로 나타났다. 이는 패스트패션 소비자들은 의복에 대한 싫증 뿐 아니라 의복변형이나 부적합 요인으로 인한 의복처분을 하 는 경우가 다소 많은 것으로 사료된다.

\section{5. 결 론}

본 연구에서는 급증하고 있는 패스트패션으로 인해 야기되 는 환경문제에 대한 해결방안 모색을 위해 패스트패션 소비자 의 의복소비행동에 대해 알아봄으로써, 패스트패션 소비자들의 소비행동에 대한 기초 자료를 제공하고, 이를 통해 소비자들이 패스트패션에서 비롯되는 의류폐기물을 줄여나가는 경제적이고 합리적인 소비행동을 할 수 있는 방향을 제시하고자 하였다. 본 연구의 결과는 다음과 같다.

첫째, 인구통계적 특성에 따른 환경인식에 대한 차이를 알아 본 결과 학력에 따라서는 유의한 차이가 있었지만 대학교 졸업 집단의 환경의식이 가장 높게 나타났고 대학원 졸업집단, 고등 학교 졸업집단 순으로 나타나 학력이 높을수록 환경의식이 높 다고 보기에는 다소 무리가 있는 것으로 사료된다.

둘째, 환경의식에 따른 패스트패션 소비자의 의복소비행동에 대해 살펴본 결과, 환경의식집단별 구매동기는 쾌락추구요인만 집단 간 유의한 차이를 보여 환경의식이 낮은 집단일수록 쾌락 적 구매를 추구하는 반면 환경의식이 높을수록 쾌락적 구매추 구가 낮음을 보여 패스트패션 구매 시에도 환경의식에 따라 구 매동기가 달라짐을 알 수 있었다. 의복사용행동에서는 환경의 식집단간 유의한 차이가 있는 것으로 나타났는데 환경의식이 높을수록 의복방치율은 낮아져 패스트패션의 저렴한 가격으로 인해 계획적이지 못한 의복사용행동을 하고 있는 것으로 볼 때 소비자들의 합리적인 의복사용행동이 요구됨을 알 수 있다. 환 경의식집단별 패스트패션 소비자의 처분행동에는 집단 간 유의 한 차이가 있었고 처분동기에 대해서는 집단 간 차이가 없는 것으로 나타났는데 처분행동에서는 환경의식이 높은 집단과 중 간집단에서 사회친화적 처분과 경제적 처분을 하는 것으로 나 타났다.

셋째, 인구통계적 특성에 따른 패스트패션 소비자의 의복소 비행동을 살펴 본 결과, 구매동기에서는 모든 요인에서 집단 간 차이를 보이는 것으로 나타났고, 특히 쾌락성 요인에서는 남성 보다 여성이 높은 점수를 보여 패스트패션 구매 시 쾌락성 추 구요인이 크게 작용함을 알 수 있었다. 따라서 이로 인한 의복 방치율이나 처분에도 영향을 미칠 것으로 사료되었다. 성별에 따른 의복사용행동에는 집단 간 유의한 차이가 있는 것으로 나 타났는데, 남성보다 여성이 비교적 의복방치율이 높은 것으로 나타나 여성이 패스트패션을 구매할 때 좀 더 합리적인 구매를 
할 필요가 있다고 사료된다. 패스트패션 소비자들의 의복처분 행동에 대한 인구통계적 특성에 따른 차이는 경제적 처분에서 남성과 여성이 차이를 보이는 것으로 나타났고 성별에 따른 차 이는 없지만 처분행동 세요인 중 편의적 처분 점수가 가장 높 게 나타난 아직도 의복처분행동의 높은 부분을 차지하고 있음 을 알 수 있었다.

이와 같은 분석결과를 바탕으로 본 연구에서는 다음과 같은 시사점을 제시하고자 한다.

첫째, 환경의식에 따른 패스트패션 소비자의 의복소비행동 중 구매행동에서 환경의식이 낮은 집단일수록 쾌락적 구매를 추구하고 환경의식이 높을수록 쾌락적 구매추구가 낮게 나타났 다. 이런 결과를 볼 때 소비자들이 환경의식에 대한 교육을 쉽 게접할 수 있게 함으로써 패스트패션 구매 시 합리적인 구매를 유도하여 의복방치율과 처분율을 줄여나가는 방안이 모색되어 야 할 것으로 사료된다. 20,30 대는 다양한 매체를 쉽게 접하 는 세대이므로 소비자들이 쉽게 접할 수 있는 인터넷이나 모바 일 매체를 통해 환경의식에 관한 정보를 제공하거나 패스트패 션 브랜드들의 환경에 대한 노력 등을 알림으로써 환경의식에 대한 교육을 자연스럽게 접하게 하는 것도 좋은 방안으로 사료 된다.

둘째, 환경의식에 따른 패스트패션 소비자의 의복소비행동 중 처분행동에서 성별에 따른 차이는 없지만 편의적 처분 요인 의 점수가 가장 높게 나타난 결과를 볼 때 패스트패션의 저렴 한 가격 특징으로 인해 쉽게 버려지는 의복폐기물들이 많은 것 으로 보여지므로 소비자들이 쉽게 의복을 처분할 수 있음과 동 시에 처분된 의복을 재활용 할 수 있는 방안에 대한 모색도 필요한 것으로 보인다. 실제로 의류분리수거함의 경우 제대로 관리되지 않거나 수거된 의류들이 제대로 재활용되지 못하는 경우가 많으므로 보다 효율적인 관리가 필요한 것으로 보여지 며 재활용될 의류폐기물을 좀 더 깨끗하게 처분하는 소비자들 의 의식도 필요하지만 이에 대한 국가나 지역단체들의 홍보도 필요할 것이라 사료된다.

셋째, 환경의식에 따른 패스트패션 소비자의 처분행동에서 사회친화적 처분과 경제적 처분이 아직도 편의적 처분에 비해 다소 낮게 나타난 것을 볼 때 쉽게 친환경적 의복처분행동을 할 수 있도록 하는 방안이 필요한 것으로 사료된다. 최근 소비 자들에게 헌옷을 수거하여 난민에게 보내는 유니클로의 리사이 클운동은 소비자들이 매장에 방문하여 손쉽게 친화경적인 처분 행동을 할 수 있게 하므로 호응을 얻고 있는데 앞으로도 패스 트패션 기업들은 소비자들이 편리하게 친환경적 처분행동을 할 수 있도록 유도할 수 있는 다양한 방안을 모색하여야 할 것으 로 사료된다.

이상으로 환경의식에 따른 패스트패션의 의복소비행동에 대 해 알아봄으로써 패스트패션으로 야기되는 의류폐기물로 인한 환경오염을 줄여나가기 위한 방안을 모색하였다. 하지만 본 연 구가 20 30대 연령의 부산 거주자에 한정되어 진행되었으므로 연령별에 맞는 소비행동에 대한 분석이 부족하고 집단 간 차이
비교에 다소 어려움이 있다고 사료되므로 향후 다양한 연령과 지역을 대상으로 한 의복소비행동을 연구함으로써 보다 다양한 방안을 모색해보는 것도 의미있을 것으로 사료된다. 또한 의복 소비행동 중 처분행동에 대한 보다 구체적인 연구를 수행함으 로써 패스트패션의 의류폐기물을 줄여나가는데 도움이 될 만한 다양한 방안에 대해 심도있게 연구해보는 것도 의미있을 것으 로 사료된다.

\section{감사의 글}

이 논문은 2012년 정부(교육부)의 재원으로 한국연구재단의 지원을 받아 수행된 연구임(NRF-2012S1A5B5A07036863).

\section{References}

An, K. H., \& Lim, B. H. (1999). Principles of marketing research. Paju: Bobmunsa.

Chang, A. R. (2007). Development of Korean style SPA of fast fashion for consumer needs. Korea Associastion of Human Ecology, 16(5), 997-1006

Chang, G. H. (1996). A study on socially responsible clothing disposition behavior. Unpublished master's thesis, Hanyang University, Seoul.

Cheon, J. E. (1999). The study on the middle school student's consciousness and behavior of the environmental problems toward their lifestyle. Unpublished master's thesis, Dong-A University, Busan.

Choi, N. S. (1995). A study on the influence of environmental education and environmental consciousness to the environmental behavior. Journal of the Korean Home Economics Association, 32(5), 29-44.

Doosan Encyclopedia. (2010). Seoul: Doosan Donga.

Han, S. H. (2009). A study on the purchasing behavior and usage of environmentally friendly clothing and the disposal of clothing. Journal of Korean Home Management Association, 27(3), 61-77.

Henion, K. E. (1972). The effect of ecologically relevant information on detergent sales. Journal of Marketing Research, 9, 10-14.

Jang, K. M. (2009). Study on fast fashion on individual shop characteristics -Focusing on dongdaemoon fashion valley and SPA brands-. Unpublished master's thesis, Ewha Womans University, Seoul.

Kang, J. H., \& Sung, Y. Y. (2010). The impact of information technology on the process innovation and competitiveness in the fashion industry -Case study of fast fashion: ZARA-. Journal of the Korean Society of Clothing and Textiles, 34(1), 1-13.

Kang, Y. H., \& Hwang, J. S. (2007). The effect of shopping orientations of male and female consumers on the attitude toward sales clerk's service and shopping environments. Journal of the Korean Society of Clothing and Textiles, 31(4), 540-550.

Kim, J. H. (2010). Study on consumer image evaluation to product design of the fast fashion. Unpublished doctoral dissertation, Hanyang University, Seoul.

Kim, J. Y. (2011). Purchase in behavior and attitudes of Korean female toward global SPA brand products as determined by their shopping orientation. Unpublished doctoral dissertation, Kyunghee University, 
Seoul.

Kim, Y. D. (1995). A study on clothing purchasing behavior according the consumer's environmental awareness. Unpublished master's thesis, Chung-Ang University, Seoul.

Lim, S. J. (1992). Study on the clothing behavior of korea college women - concentrating on socio-psychological factors. Unpublished doctoral dissertation, Ewha Womans University, Seoul.

Lee, C. H. (1995). A study on the consumers' clothing management behavior and reapplication of resources related to the environmental problems. Unpublished master's thesis, Chung-Ang University, Seoul.

Lee, C. H. (1997). The study on clothing and clothing recycling status management actions related to the environmental problems of the consumer. Unpublished master's thesis, Chung-Ang University, Seoul.

Lee, J. H. (1995). Study on the use of credit cards based on clothing purchase motivations. Unpublished doctoral dissertation, Ewha Womans University, Seoul.

Lee, J. H. (2010). Shopping orientations and attitudes according to the collaboration of luxury brands and of fast fashion brands. Unpublished master's thesis, Konkuk University, Seoul.

Lee, K. J., \& Kim, Y. S. (1998). The middle and high school students' environmental consciousness and clothing behavior for environmental protection in their home. Journal of Korean Home Economics Education Association, 10(1), 1-16.

Lee, S. B. (2008). Fast fashion buyers' impulsive buying tendency and their post-purchase behaviors. Unpublished master's thesis, Dongduk Women's University, Seoul.

National Institute of the Korean Language. (2004). 2014 neologism.
Seoul: National Institute of the Korean Language.

Nicosia, F. M., \& Mayer, R. N. (1976). Toward a sociology consumption. Journal of Consumer Research, 3(2), 65-75.

Park, H. H., \& Oh, S. D. (2005). The influence of materialism and environment consciousness on recycling attitude and behavior of clothing. Journal of the Korean Home Economics Association, 43(10), 167-177.

Park, S. Y. (2009). Environmental consciousness \& clothing consumption behavior of the consumers in their 10's \& 20's. Unpublished master's thesis, Hanyang University, Seoul.

Park, U. A. (1997). Pro-environmental behavior of consumer and its related factors. Journal of the Korean Home Economics Association, 35(5), 221-237.

Ro, J. H., \& Kim, M. J. (2009). Socio-cultural interpretation of fast fashion phenomenon. Journal of the Korean Society of Costume, 59(3), 27-41.

Shim, S. (1995). Environmentalism and consumers clothing disposal patterns: An exploratory study. Clothing and Textiles Research Journal, 13(1), 28-48.

Shin, M. H. (2011). The influence of fast fashion value on commitment and repurchase intention. Korea Business Review, 24(6), 35053523.

Yoo, Y. S. (1996). A study on the women's clothing discard behavior. Journal of the Korean Society of Clothing and Textiles, 20(1), 142156.

(Received 21 April 2015; 1st Revised 25 May 2015; 2nd Revised 1 June 2015; Accepted 20 June 2015)

(C) 2015 (by) the authors. This article is an open access article distributed under the terms and conditions of the Creative Commons Attribution license (http://creativecommons.org/licenses/by/3.0/), which permits unrestricted use, distribution, and reproduction in any medium, provided the original work is properly cited. 